\title{
A.I. Driven Thermal People Counting tor Smart Window Facade Using Portable Low-Cost Miniature Thermal Imaging Sensors
}

\author{
${ }^{1}$ Moveh Samuel, ${ }^{2}$ Samuel-Soma M Ajibade, ${ }^{3}$ Fred Fudah Moveh
}

\begin{abstract}
${ }^{1}$ Intelligent control and automation (ICA) Research group department of Mechanical Engineering, Faculty of Mechanical Engineering Universiti Tecknologi Malaysia Johor Bahru, Johor Malaysia ${ }^{2}$ Universiti Teknologi Malaysia, Faculty of Computing, Department of Computer Science, Skudia, Johor Bahru, Johor, Malaysia
\end{abstract}

${ }^{3}$ Department of information technology Modibbo Adama University of Technologi Yola, Adamawa state Nigeria

\begin{abstract}
People counting applications have been used in diverse applications. The ability and accuracy of thermal imaging over conventional image cameras has led to the implementation of thermal cameras in people counting applications. This paper present a thermal people counting smart glass windows. The people counting application would be remotely monitored from a single centralized PC station as it's connected to a multiplex of mass monitoring of 20 thermal camera, all embedded into different glass windows. The thermal cameras would then be able to detect body temperatures of all individuals who pass through any of the camera range and also count the numbers of people who passed through the camera range. The data gotten can then be further utilized in various ways, example is in the control of air conditioning and lightening.
\end{abstract}

IndexTerms - counting; imaging; people; thermal

\section{INTRODUCTION}

$\mathrm{T}$ hermal imaging is a non-contact temperature measurement technology which can provide remote monitoring of the thermal distributions, and further be applied in the cloud IoT, big data analytics, securing monitoring with no privacy involved. As a main application, people counting is a vital task for operational, safety and security functions. Systems with these functions are often extremely effective tools for establishing awareness [1], [5]. Information about the amount and distribution of individuals in a very given space are often used to develop business intelligence, like the interest on some product can be evaluated by the amount of shoppers visiting the area, count the amount of a store's guests and different applications in behavioral economics [2], [6], [7]. Other areas where people counting is helpful are crowd management [2], transport [8], and staff planning which are related to the density of people traffic or to indicate congestion. This kind of information can also be utilized in several ways. Also real-time people counting in either normal camera mode or people counting in thermal camera mode has been found to be resourceful in some applications. Some of such applications include security, smart buildings, or people management such as in pedestrian traffic management or tourists flow estimation and also improve energy efficiency by optimizing air conditioning, lighting and heating, or to develop emergency evacuation procedures [3].
Over the years several methods have been used to count people, such as tally counter, infrared beams, thermal imaging, computer vision, Service Set Identifier (SSID) from mobile phones, wireless sensor networks and Wi-Fi based counters [9], [10], [11], [12], [13], [14], [15], [16], [17], [18]. But as time passed, computer vision video analytics, where people are counted via a live cameras stream has increased considerably, as a result of the advancement of image processing algorithms and computers' technology. In the study of [19] an adaptive crowd counting system for video surveillance applications was developed based on pair of collaborative Gaussian process models (GP) with different kernels, which are designed to count people using normal camera by taking the level of occlusion into Account. Their results indicated that the level of accuracy of method adopted was poor, due to the presence of image noise. The method didn't take into account the fact that in every image there exist sets of noise that needs to be filtered for better pixel estimation. [20] modified the prevailing method but instead they used face detection technics and tested in different scenarios, their application worked but failed in certain instances, one of the very obvious reasons is when a face isn't well detected. Examples is in a crowed place not all faces ate directly facing the camera. So for this method to be accurate all faces must face the camera. Another very crucial area where the use of camera fail was in detection at night, since the camera can only capture proper and clear face in the presence of light. This lead to the use of thermal imaging cameras for proper counting of people in any condition, either day or night. [21] developed a software that counts people using an identifier and the software was connect via USB, this technic performed poorly because The visual analysis was done using background identification technique. Rather than run proper image processing algorithm from stages to stages, an identifier was used to perform the counting. The issue of osculation and poor lightening was taking into account in [21], [22] where they try to address the challenges due to changing lighting conditions and the complexity of scenes with many people occluding one another. Their method was tested on two five-minute video sequences captured at a public event with a moderate density of pedestrians and heavy occlusions. But results indicated poor performance when tested on live video stream.

Although most of this method seem simple though; there are 
some situations difficult to solve even with today's computer speeds (the algorithm has to operate in real-time, so it makes limits for the complexity of methods for detection and tracking), one of such difficulties is people occlusions. Other issues with visual counting system is the cost. High spatial resolution visual camera and a frame grabber are required which makes the system expensive. Even with high spatial resolution cameras the inaccuracy problem still remains for detection of people. Say if a person is wearing same shades of grey as of background it will be difficult to distinguish between the background and same shades of cloths.

Also there is no such ways of distinguishing with accuracy a person from different objects. These objects in the background are one of the main concerns that raised false alarms in many automated people counting systems. Whereas the background separation is not the easy task. Visual automated counting systems can only work in the presence of ambient lighting such as office environment, sunlight, or other interior types of lighting. In case of emergencies like fire, blackouts the system will malfunction during evacuation of the building thus will render useless during emergencies. Similar case is with exterior use of people counters [5], there will be false alarms during night time by the counting system if there is no special lighting arrangement in the area under consideration.

Table 1 gives a categorized review of existing people counting applications.

Table 1: Review of People counting Applications

\begin{tabular}{|c|c|c|c|c|c|}
\hline $\begin{array}{l}\text { Authors } \\
\text { and yeah }\end{array}$ & $\begin{array}{l}\text { Title, and } \\
\text { Journal }\end{array}$ & $\begin{array}{l}\text { Objectives } \\
\text { of study }\end{array}$ & $\begin{array}{l}\text { Methodol } \\
\text { ogy and } \\
\text { Material }\end{array}$ & $\begin{array}{l}\text { Remark/Observa } \\
\text { tions }\end{array}$ & Ref \\
\hline $\begin{array}{l}\text { Zeyad } \\
\text { Q.H. } \\
\text { Al-Zaydi } \\
\text { L. David } \\
\text { L. Ndzi, } \\
\text { Yanyan } \\
\text { Yang, } \\
\text { Munirah } \\
\text { L. } \\
\text { Kamarud } \\
\text { in }\end{array}$ & $\begin{array}{l}\text { An } \\
\text { adaptive } \\
\text { people } \\
\text { counting } \\
\text { system } \\
\text { with } \\
\text { dynamic } \\
\text { features } \\
\text { selection } \\
\text { and } \\
\text { occlusion } \\
\text { Handling } \\
\text { Journal } \\
\text { of Visual } \\
\text { Commun } \\
\text { ication } \\
\text { Image } \\
\text { Represen } \\
\text { tation. }\end{array}$ & $\begin{array}{l}\text { Create an } \\
\text { adaptive } \\
\text { crowd } \\
\text { counting } \\
\text { system for } \\
\text { video } \\
\text { surveillance } \\
\text { applications }\end{array}$ & $\begin{array}{l}\text { Method is } \\
\text { composed } \\
\text { of a pair of } \\
\text { collaborati } \\
\text { ve } \\
\text { Gaussian } \\
\text { process } \\
\text { models } \\
\text { (GP) with } \\
\text { different } \\
\text { kernels, } \\
\text { which are } \\
\text { designed } \\
\text { to count } \\
\text { people } \\
\text { using } \\
\text { normal } \\
\text { camera by } \\
\text { taking the } \\
\text { level of } \\
\text { occlusion } \\
\text { into } \\
\text { Account. } \\
\text { The level } \\
\text { of } \\
\text { occlusion } \\
\text { is } \\
\text { measured } \\
\text { and } \\
\text { compared } \\
\text { with a a } \\
\text { predefined } \\
\text { threshold } \\
\text { for } \\
\text { regression } \\
\text { model } \\
\text { selection } \\
\text { for each } \\
\text { frame }\end{array}$ & $\begin{array}{l}\text { The level of } \\
\text { accuracy of these } \\
\text { method was poor, } \\
\text { due to the presence } \\
\text { of image noise. } \\
\text { The method didn't } \\
\text { take into account } \\
\text { the fact that in } \\
\text { every image there } \\
\text { exist sets of noise } \\
\text { that needs to be } \\
\text { filtered for better } \\
\text { pixel estimation }\end{array}$ & [19] \\
\hline $\begin{array}{l}\text { H.Hakan } \\
\text { Cetinkay } \\
\text { aa, } \\
\text { Muamme } \\
\text { r Akcayb }\end{array}$ & $\begin{array}{l}\text { People } \\
\text { Counting } \\
\text { at } \\
\text { Campuses }\end{array}$ & $\begin{array}{l}\text { Objective of } \\
\text { this study } \\
\text { was aim at } \\
\text { automatically } \\
\text { estimating } \\
\text { the number } \\
\text { of people in }\end{array}$ & $\begin{array}{l}\text { Estimating } \\
\text { the } \\
\text { number of } \\
\text { people } \\
\text { through a } \\
\text { camera in } \\
\text { Several }\end{array}$ & $\begin{array}{l}\text { This method didn't } \\
\text { perform well } \\
\text { because of very } \\
\text { obvious reasons } \\
\text { like when a face } \\
\text { isn't well detected. } \\
\text { Examples is in a }\end{array}$ & [20] \\
\hline
\end{tabular}

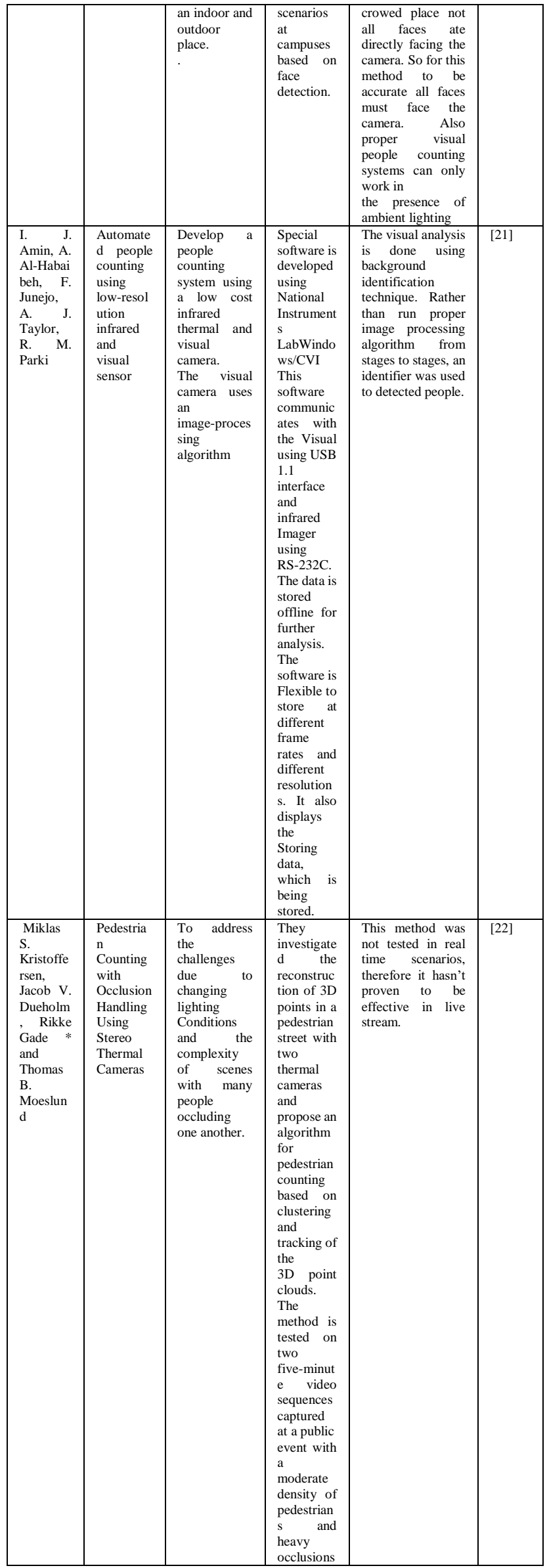




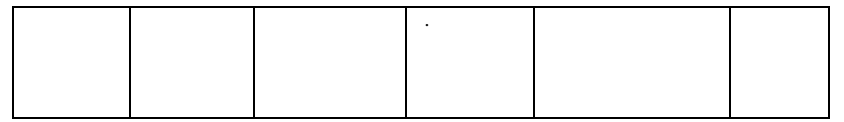

Thus, in summary based on the findings in literature, existing methods are based on skin detection, which provide inaccurate count, method involves complex algorithms and difficult to compute the faces and all these methods of people counting involves a lot of hardware components. This paper therefore, presents an AI based thermal people counting application for smart window façade using a low cost thermal visual camera. The people counting application will use an AI based image-processing algorithm that would take into account facial and body detection with less hardware and would be able to distinguish between people and objects, and count accurately.

\section{Computer vision Video Analytics}

Video analytics, or intelligent video analytics, is software that is used to monitor and process video streams or images in real-time. While tracking the videos or pictures, the software identifies attributes, events or patterns of specific behavior via video or image analysis of monitored environments. Video analysis software also generates automatic alerts and can facilitate forensic analysis of any data identifying trends, patterns and incidents. The software enables its users to analyses, organize and share any insight gained from the data to make smarter, better decisions. Some of the common areas of application of video analytic are widespread, including monitoring vehicle patterns or violations of traffic laws, or people counting. The data received from either of these applications can then be sorted by time and date or over an extended period to create a trend analysis.

Video analytics comes with many benefits in security for public safety and in smart building applications. It is being proposed and used to enhance these two sectors with comprehensive intelligence, security and investigative capabilities. Therefore the developed AI based thermal people counting analytic software would be used to estimate the number of persons in the building at any particular time. This Application will run the AI based image processing algorithm that will automatically determining the number of people and objects in a thermal video stream. Once the number of objects is determined the objects per unit area or the density can also be estimated. The method would involve counting based on the area of objects, the color of objects, applying edge detection techniques, face detection and body detection algorithm.

\section{Methodology}

People counting software is an application used in calculating the number of people in thermal video stream or images. Since computing, the number of objects is an integral part of image processing. Knowing the number of objects present in an image by using the expression in Eq 1, the information gotten can then be useful for further analysis in a wide range of applications. This Application proposes a simple method for automatically determining the number of objects in a thermal image. Once the number of objects is determined the objects per unit area or the density can also be estimated. The method would involve counting based on the area of objects, the color of objects, applying edge detection techniques.

OBJECTS PER UNIT AREA = NO OF OBJECTS TOTAL SIZE OF IMAGE

(Eq 1)

\section{Thermal People Count}

The goal of people counting is to estimate the number of people or the density of crowds in a monitored environment. Since it is a fact that long-term and short-term statistics of people counts of an environment provide useful information for strategy planning or event detection. However, detecting or estimating the density of crowds is always a challenging task due to some of the issues stated earlier, such as partial occlusions, low-quality images, clutter backgrounds, and so on.

Two primary technique would be used to count people in the thermal image. The first technique would be to count people based on face detection. Face detection is the process in which possible human faces are detected from a thermal image. Once the number of faces is detected, the density can be calculated, and rectangular boxes would be used to map the faces in the thermal image, as seen in figure 1a below.

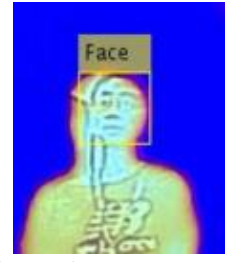

Figure 1a: Face detection

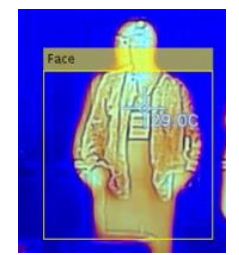

Figure 1b: Body Detection
The second technique used in determining the number of people in a thermal image is by possible body detection. Some thermal photos might not have clear possible head faces of people in it. But with the help of the human figure body detection technique, the people counter application can calculate the number of persons in the thermal image as seen in a figure $1 \mathrm{~b}$

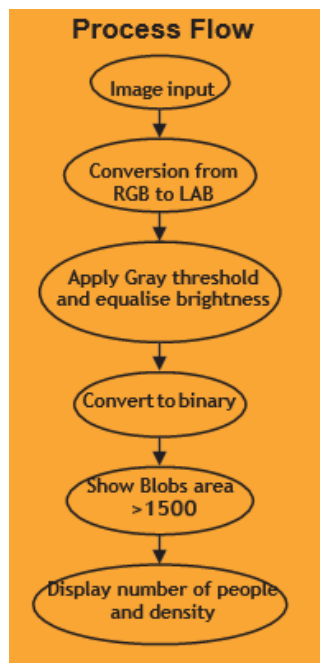

Figure 2: People Counting Algorithm Process flow

Figure 2 shows the intelligent image processing processes carried out when the thermal people counting application is 
running. Screenshots of the processes can be seen in discussion section of results

\section{DISCUSSION OF RESULTS}

\section{Thermal Imaging Processing}

All objects emit heat by three means: Conduction, convection and radiation. Conduction transfers heat through solid objects. Convection transfers heat through fluids like air and water. Radiation transfers heat through electromagnetic radiation. Objects continuously radiate heat with certain wavelength. Therefore, thermal imaging converts thermal radiation into digital signal and which is converted into visible image.

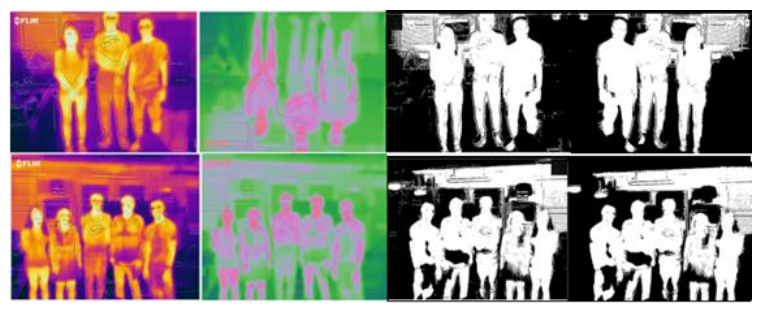

Figure 3: thermal people counting stages

Figure 3 shows the stages involved in the thermal people counting application, the thermal feed is converted from thermal view to lab

Brightness equalization is done, and. the equalized image is converted to binary. The blobs in the thermal feed are opened when the blobs area is greater than 1500 . The number of people and density are displayed. Also facial skin temperature features and gender differences were estimated using eq 2 as seen in [23]

$$
\rho=\frac{1}{n} \sum_{k=1}^{n} \mu_{k}, \quad S D(\rho)=\sqrt{\frac{1}{n-1} \sum_{k=1}^{n}\left(\mu_{k}-\rho\right)^{2}}
$$

(Li et al., 2019)

\section{APPLICATION}

\section{People Counting}

There are several applications of people counting technologies, ranging from counting people in a mall or an office building to counting of pedestrian and even counting of vehicle as well. However the essence of this was to study the possibility of connecting 20 multiplex thermal cameras from a single PC station. We had achieve that goal of successfully connect all 20 thermal cameras to a single work station PC. The next step was to embed thermal camera into glass windows and use it not just counting the number of people in the room but also to determine the thermal comfort level of the room and hence control the air conditioning and lightening of the room so as to save energy.

As can be seen in figure $4 \mathrm{a}$ and $4 \mathrm{~b}$, a test was done by connecting a single thermal camera to the thermal people counting application. The thermal camera was embedded into the glass widow as in figure.

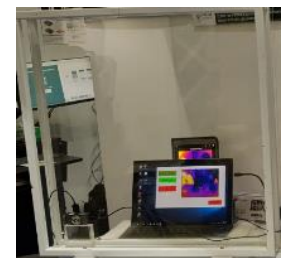

Figure 4a: Smart Glass window Embedded with thermal camera

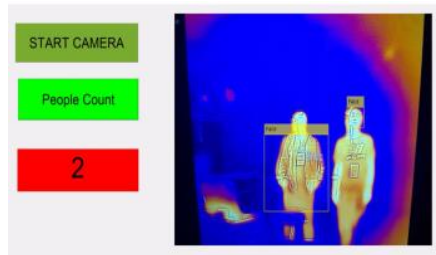

Figure 4b: AI based thermal People Counting app
Every individual that passed through the thermal camera coverage area was detected and counted as seen in figure $4 \mathrm{~b}$ and their body temperature was recorded also The camera has a maximum coverage range of 30 meters..

After testing the countability and precision of the counting application, the glass window was installed on a climate chamber for environmental indoor and outdoor monitoring, so as to determine the estimate of average thermal comfort level of the space in addition to monitoring the environment and counting of people both in and around the thermal camera coverage area

\section{THE GOAL HERE WAS TO BE ABLE TO AUTOMATICALLY ESTIMATE THE COMFORT LEVEL BASED ON THE COUNTING OUTPUT TO CONTROL THE AIR-CONDITIONING. THAT IS IF THE PEOPLE COUNTING APPLICATION DETECTS 100 PERSONS, 5 CHILLERS COULD AUTOMATICALLY TURNED ON AND IF THE NUMBER DETECTED IS JUST ONE PERSON, ONLY ONE CHILLER WOULD BE TURN ON. BY SO DOING ENERGY CONSUMED CAN BE GREATLY REDUCED. CONCLUSION}

The goal of this study was to develop and test an AI based thermal people counting application with a Smart glass window façade. The application was tested and a precise and accurate count was recorded for all individuals who came into the thermal camera range of view. Their body temperatures were also recorded at the exact time each individual was counted. The test was carried out in both night and day and the result still was accurate. The data gotten from the count and the data of the body temperature can then be used for energy efficacy operations like control of air-conditioning and lightening. This technology has proven to be effective in implementing in smart concept buildings.

\section{REFERENCES}

[1] D. Ryan, S. Denman, C. Fookes, and S. Sridharan, "Scene invariant multi camera crowd counting," Pattern Recognition. Lett., vol. 44, pp. 98-112, 2014.

[2] A. Technology, "Our customers," 2013. [Online]. Available: www.peoplecounting.co.uk/our-customers. [Accessed: 23-Mar-2015].

[3] M. Wang, "Data Assimilation for Agent-Based Simulation of Smart Environment," 2014.

[4] D. A. Ryan, "Crowd Monitoring Using Computer Vision," Queensland University of Technology, 2013.

[5] C. Loy, K. Chen, S. Gong, and T. Xiang, Crowd counting and profiling: Methodology and evaluation. 2013.

[6] ShopperTrak, "ShopperTrak Solutions," 2013. [Online]. Available: www .shoppertrak.com / products. [Accessed: 23-Mar-2015]. 
[7] Biodata Ltd, "Use CCTV to Count People," 2013. [Online]. Available: www.videoturnstile.com. [Accessed: 23-Mar-2015].

[8] DILAX Intercom, "Public Transport," 2015. [Online]. Available:

www.dilax.net/electronic-peoplecounter-passenger-counte r-customer-counter/passenger-counting-systems-for-publi c-transportation. [Accessed: 23-Mar-2015].

[9] F. Z. F. Zhu, X. Y. X. Yang, J. G. J. Gu, and R. Y. R. Yang, "A New Method for People-Counting Based on Support Vector Machine," 2009 Second Int. Conference on Intelligent. Networks Intelligent. System. vol. 1, no. 5, pp. 5-8, 2009.

[10] N.-N. Li, J. Song, R.-Y. Zhou, and J.-H. Gu, "A People-Counting System Based on BP Neural Network," Fourth Int. Conf. Fuzzy Syst. Knowledge. Discovery. (FSKD 2007), vol. 3, no. Fskd, 2007.

[11] M. Nakatsuka, H. Iwatani, and J. Katto, "A Study on Passive Crowd Density Estimation using Wireless Sensors," 4th Intl. Conf. $\sim$ on Mob. Comput. Ubiquitous Netw. (ICMU 2008), no. 2, pp. 1-6, 2008.

[12] Z. Ma and A. B. Chan, "Crossing the line: Crowd counting by integer programming with local features," Proc. IEEE Comput. Soc. Conf. Comput. Vis. Pattern Recognit., pp. 2539-2546, 2013.

[13] Y. Yuan, C. Qiu, W. Xi, and J. Zhao, "Crowd Density Estimation Using Wireless Sensor Networks," 2011 Seventh Int. Conf. Mob. Ad-hoc Sens. Networks, pp. 138-145, 2011.

[14] R. Shbib, S. Zhou, D. Ndzi, and K. Al-kadhimi, "Distributed Monitoring System Based On Weighted Data Fusing Model," Am. J. Soc. Issues Humanit., vol. 3, no. March, pp. 53-62, 2013.

[15] W. Xi, J. Zhao, X. Y. Li, K. Zhao, S. Tang, X. Liu, and Z. Jiang, "Electronic frog eye: Counting crowd using Wi-Fi," Proc. - IEEE INFOCOM, pp. 361-369, 2014.

[16] W.-C. Lin, W. Seah, and W. Li, "Exploiting radio irregularity in the Internet of Things for automated people counting," IEEE Int. Symp. Pers. Indoor Mob. Radio Commun. PIMRC, pp. 1015-1019, 2011.

[17] V. Gandhi, J. Čech, and R. Horaud, "High-resolution depth maps based on TOF-stereo fusion," Proc. -IEEE Int. Conf. Robot. Autom., pp. 4742-4749, 2012.

[18] Y. L. Hou and G. K. H. Pang, "People counting and human detection in a challenging situation," IEEE Trans. Syst. Man, Cybern. Part ASystems Humans, vol. 41, no. 1, pp. 24-33, 2011.

[19] Al-Zaydi, Z. Q. H. et al. (2016) 'An adaptive people counting system with dynamic features selection and occlusion handling', Journal of Visual Communication and Image Representation. Elsevier Inc., 39, pp. 218-225. doi: 10.1016/j.jvcir.2016.05.018.

[20] Cetinkaya, H. H. and Akcay, M. (2015) 'People Counting at Campuses', Procedia - Social and Behavioral Sciences. Elsevier B.V., 182, pp. 732-736. doi: 10.1016/j.sbspro.2015.04.821

[21] [1] M. Samuel, M. Mohamad, S. M. Saad, and M. Hussein, "Development of Edge-Based Lane Detection Algorithm using Image Processing," JOIV Int. J.

Informatics Vis., vol. 2, no. 1, pp. 19-22, 2018.
[2] M. Samuel, M. Mohamad, M. Hussein, and S. Saad, "Development of Lane keeping Controller Using Image processing," Int. J. Comput. Netw. Technol., vol. Volume 6, no. Issue 3, pp. 0-4, 2018.

[3] M. Samuel, "Comparative Analysis of Lane Detection Method Using Matlab," no. December, pp. 25-31, 2016. 